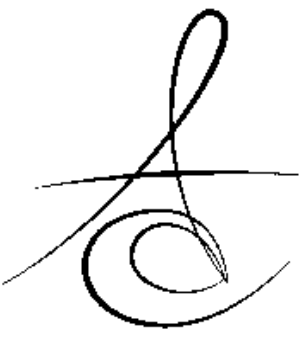

\section{RİNOPLASTİ NEDENİYLE RETROMOLAR ENTÜBASYON YAPILAN HASTADA BİLATERAL SAGİTTAL SPLİT RAMUS OSTEOTOMİSI}

\author{
RETROMOLAR INTUBATION IN A PATIENT WITH RHINOPLASTY \\ UNDERGOING BILATERAL SAGITTAL SPLIT RAMUS OSTEOTOMY
}

\author{
Yrd. Doç. Dr. Ahmet ALTAN* \\ Doç. Dr. Ziya KAYA** \\ Yrd. Doç. Dr. Esengül ŞEN*
}

Makale Kodu/Article code: 2697

Makale Gönderilme tarihi: 23.03.2016

Kabul Tarihi: 05.05.2016

\section{öz}

Bu vaka raporunda; bilateral sagittal split ramus osteotomisi planlanan hastada, geçirmiş olduğu rinoplasti ameliyatları nedeniyle retromolar entübasyonla yapılan ortognatik cerrahinin sunumu amaçlanmıştır.

Mandibular deformitesi olan 22 yaşındaki bayan hasta Ağız Diş ve Çene Cerrahisi kliniğine başvurdu. Hastada bilateral sagittal split ramus osteotomisi yapılarak alt çenenin $6 \mathrm{~mm}$ geri alınması planlandı. Genel anestezi öncesinde rutin hazırlıklarında hastanın 3 ay önce rinoplasti yaptırdığı öğrenildi. Rinoplasti işlemi sonrası elde edilen estetik görünümün bozulmaması için nazal entübasyondan vazgeçildi. Ameliyat sırasında oklüzyon kontrollerini etkilemeyecek şekilde retromolar entübasyon yapılarak hasta başarılı bir şekilde opere edildi. Hava yolu güvenliğini sağlamada sıklıkla kullanılan oral ve nazal entübasyon her zaman uygulanamayabilir. Retromolar bölgede yeterli boşluk varsa retromolar entübasyon tekniği ortognatik cerrahi ameliyatlarında alternatif bir yöntem olarak düşünülebilir.

Anahtar Kelimeler: entübasyon, ortognatik cerrahi, retromolar

\section{ABSTRACT}

In this case report, we aimed to present retromolar intubation in a patient undergoing bilateral sagittal split ramus osteotomy. Nasal entubation was impossible for this patient with rhinoplasty.

A-22-year old female with mandibular deformity was referred to the Department of Oral and Maxillofacial Surgery. Orthognathic surgery was planned as a first surgery concept according to patient's individual and orthodontist request. Bilateral sagittal split osteotomy was planned for mandibular setback. Patient has been operated for rhinoplasty by her plastic surgeon three months ago. Because of adverse effects and risks of damage to rhinoplasty, nasotracheal intubation was contraindicated. Retromolar intubation was preferred. This tecnique allowed intraoperative assessment ofthe occlusion and maxillomandibular fixation during the operation.

Sometimes orotracheal and nasotracheal intubation are contraindicated. In the presence of enough space in the retromolar region, retromolar intubation techniques in orthognathic surgery can be considered as an alternative method of operation.

Key Words: intubation, orthognathic surgery, retromolar

büyük çoğunluğunda oral entübasyon yapılarak hava yolunun kontrolü ve korunması sağlanır ${ }^{1}$. Yapılacak entübasyonun türü, cerrahi uygulanacak alana ve hastanın hava yolu anatomisine göre değişiklik gösterir².

Maksillofasiyal bölgede yapılan travma ve ortognatik cerrahi gibi ameliyatlarda operasyon sağlayan önemli basamaklardan biridir. Vakaların

\footnotetext{
* Gaziosmanpaşa Üniversitesi, Diş Hekimliği Fakültesi Ağız-Diş ve Çene Cerrahisi A.D

** Gaziosmanpaşa Üniversitesi, Tıp Fakültesi Anesteziyoloji ve Reanimasyon A.D.,
} 
sırasında oklüzyon kontrolü gerektiği için standart yöntem olan oral entübasyon yapılamaz. Bu nedenle maksillofasiyal bölgede yapılan birçok ameliyatta nazal entübasyon tercih edilir ${ }^{3}$. Nazal entübasyon oral entübasyona göre daha travmatik ve daha fazla zaman alan bir yöntemdir ${ }^{4}$. Gelişimsel malformasyonlar (nazal septum deviasyonu, nazal kavite polipozisi, dar veya eğri nazal kanal, obtruktif mukozal şişme) ${ }^{5}$ ve kafa tabanı kırığı, rinoplasti ${ }^{6}$ nazal entübasyonun kontrendike olduğu durumlardır. Bu gibi durumlarda submental entübasyon ${ }^{7}$, trakeostomi ${ }^{8}$ veya retromolar entübasyon ${ }^{9}$ hava yolu güvenliğini sağlamak için alternatif yöntemler olarak düşünülebilir.

Martinez-Lage ve ark. 10 tarafından, kraniofasiyal ve ortognatik cerrahi ameliyatlarında geleneksel yöntemlere bağlı komplikasyonların önlenmesi için tarif edilen retromolar entübasyon diğer tekniklere göre daha az invaziv bir yöntemdir. Retromolar bölge son büyük azı diş ile ramusun ön kenarı arasında yer almaktadır. Bu boşluk kullanılarak oklüzyonu etkilemeyecek şekilde entübasyon yapılabilir.

Bu vaka raporunda; bilateral sagittal split ramus osteotomisi planlanan hastada geçirmiş olduğu rinoplasti ameliyatları nedeniyle retromolar entübasyonla yapılan ortognatik cerrahinin sunumu amaçlanmıştır.

\section{OLGU SUNUMU}

Mandibular deformitesi olan 22 yaşındaki bayan hasta Ağız Diş ve Çene Cerrahisi kliniğine Ortodonti Anabilim Dalı́ndan sevk edildi. Hastanın şikayeti; estetik olmayan yüz görünümü ve alt çenenin önde olmasıydı. Hastanın ve ortodontistin istekleri doğrultusunda; hastada önce cerrahi işlem daha sonra ortodontik tedavi şeklinde bir plan yapıldı. Cerrahi öncesinde intermaksiller fiksasyon için gerekli olan looplu arklar hazırlanarak hastaya uygulandı. Hastanın modelleri alınarak akrilik splint hazırlandı. Hastada bilateral sagittal split ramus osteotomisi yapılarak alt çenenin $6 \mathrm{~mm}$ geri alınması planlandı.

Genel anestezi öncesinde rutin hazırlıkları yapılan hastanın daha önce rinoplasti yaptırdığı ve üç ay öncesinde bu işlemin revize edildiği öğrenildi. Rinoplasti işlemi sonrası elde edilen estetik görünümün bozulmaması için anestezist ve kulak, burun, boğaz uzmanlarının görüşleri doğrultusunda nazal entübas- yondan vazgeçildi. Yapılan klinik muayenede yirmi yaş dişleri çekilen hastada retromolar bölgedeki boşluğun entübasyon tüpününün yerleştirilmesi için uygun olduğu görüldü (Resim-1). Genel aneztezi uzmanıyla yapılan konsültasyonda; bayan hastalarda iç çapı en az $6 \mathrm{~mm}$ olan entübasyon tüpüyle sağlıklı bir entübasyon yapılabileceği öğrenildi. Ameliyat sırasında uygulanan basınçtan etkilenmemesi için spiralli entübasyon tüpününü daha uygun bir tercih olacağı öğrenildi. Hastada retromolar bölgedeki boşluğun yeterli olmasından dolayı iç çapı $7 \mathrm{~mm}$, dış çapı 9,3 mm olan spiralli entübasyon tüpü kullanıldı (Resim-2). Hasta oklüzyon kontrollerini de etkilemeyecek şekilde retromolar entübasyonla uyutuldu. Entübasyon tüpü dudak kenarına sabitlendi, maksilla posterior dişlerin vestübülünde konumlandırıldı (Resim-3). Hastanın sadece alt çenesinde işlem yapılacağından tüpün konumu sağ ve sol osteotomiler yapılırken değiştirilmedi. Ameliyat esnasında ekartörlerle dikkat edilerek tüpün flep dışında, yanak tarafında kalması sağlandı.

Entübe edilen hastada gerekli insizyonların ardından flep kaldırıldı ve piezocerrahi yardımıyla osteotomiler gerçekleştirildi. Osteotomlar kullanılarak kemik kesileri derinleştirildi. Kemik fragmanları inferior alveolar nörovasküler demet korunarak birbirinden ayrıldı. Aynı işlemler iki tarafta da uygulandı. Ortodonti bölümünün hazırladığı akrilik splintle çeneler istenilen şekilde konumlandırıldı ve intermaksillar fiksasyon yapıldı. Proksimal segmentlerden $6 \mathrm{~mm}$ alınarak alt çene geri alındı. Plak vida kullanılarak çift taraflı fiksasyon yapıldı. Retromolar bölgede konumlanan entübasyon tüpü sayesinde çene hareketleri ve oklüzyon rahatlıkla kontrol edildi. Ameliyat bölgesi 3.0 ipek kullanılarak primer olarak kapatıldı ve operasyon sonlandırıldı.

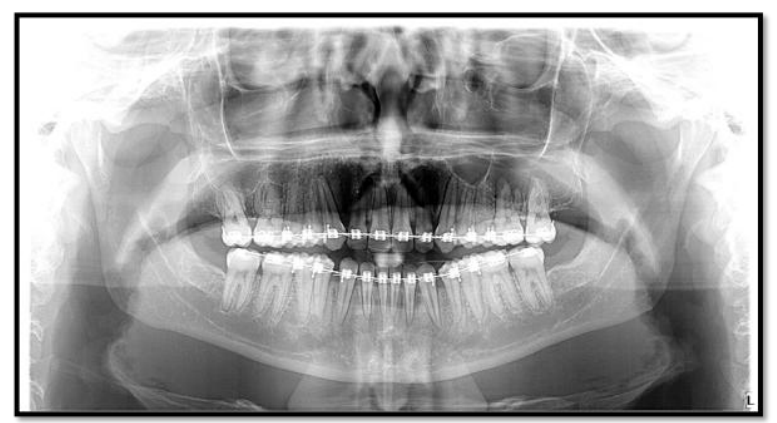

Resim-1. Panaromik radyografide retromolar bölgede entübasyon tüpü için yeterli boşluk görülmekte 


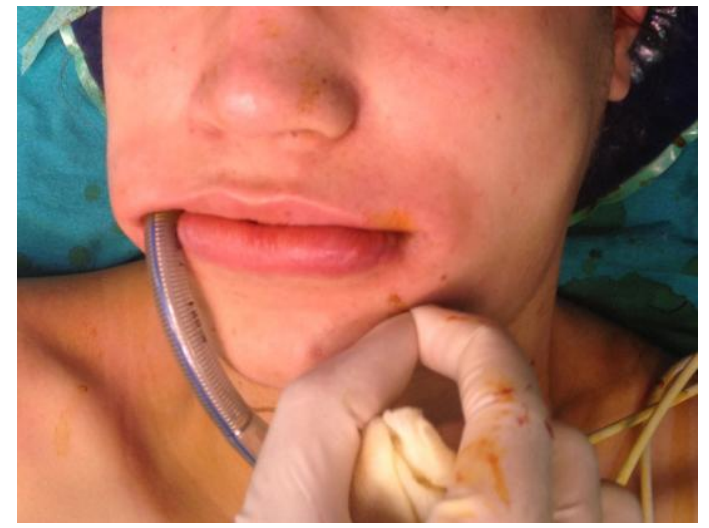

Resim-2. Sağ retromolar bölgede konumlanan iç çapı $7 \mathrm{~mm}$, dış çapı 9,3 mm olan spiralli entübasyon tüpü

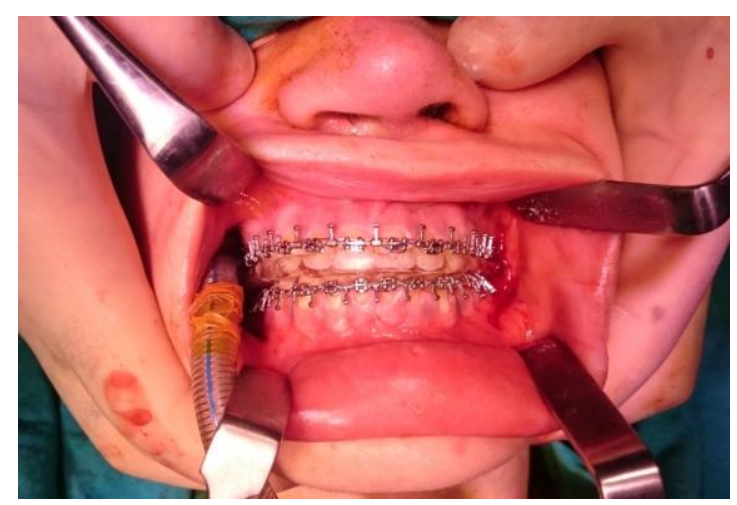

Resim-3. Dudak kenarına sabitlenen entübasyon tüpünün ağız içi konumu

\section{TARTIŞMA}

Operasyon sırasında intermaksillar tespit ve oklüzyon kontrolü gerektiren durumlarda oral entübasyon mümkün değildir. Böyle bir durumda nazal entübasyon, submental entübasyon trakeostomi ve daha az invaziv olan retromolar entübasyon alternatif olarak düşünülebilir. Retromolar entübasyon ilk olarak Martinez-Lage ve ark. ${ }^{10}$ tarafından tarif edilmiştir. Bu yöntemde molar dişlerin bittiği yerden entübasyon tüpü yerleştirilir. Ortognatik cerrahi ve maksillofasiyal travma operasyonlarında nazal enübasyon kontrendikasyonu varsa oklüzyon kontrolünü etkilemeyen ve daha az invaziv olan bir yöntemdir. Retromolar bölgede entübasyon tüpü için yeterli miktarda boşluk oluşturabilmek için ramusun ön kenarından kemik kaldırıması tavsiye edilmiştir ${ }^{10}$. Ancak bu kemik yıkımına neden olduğu için ve işlem süresini uzattığı için eleştirilen bir yöntemdir ${ }^{4}$. Gibbons ve ark. ${ }^{9}$ bir travma vakasında fonksiyonel olmayan üçüncü molar dişin çekiminden sonra retromolar entübasyon yapmıştır. Dutta ve ark. ${ }^{11} 42$ yetişkin hastada yaptıkları gözlemlerde retromolar bölgenin endotrakeal tüpün yerleştirilmesi için yeterli boşluğa sahip olduğunu rapor etmişlerdir. Ancak üçüncü molar dişlerin gömülü ya da sürmüş olması retromolar bölgedeki genişliğin boyutlarını önemli derecede etkilemektedir. Sunulan vakada ortognatik cerrahi planlanan hastada osteotomilerin olumsuz etkilenmemesi için yirmi yaş dişlerinin çekimi ameliyat öncesinde gerçekleştirilmişti. Böylelikle retromolar bölgede $7 \mathrm{~mm}$ çaptaki spiralli tüple entübasyon rahatlıkla yapılabildi.

Panaromik radyograflar endotrakeal tüpün yerleştirilmesi için retromolar alan yeterliliğini değerlendirmede yardımcı olabilir. Ancak elde edilen iki boyutlu görüntü yanıltıcı olabilir ${ }^{4}$. Retromolar bölgedeki alanın yeterliliğini tespit etmede kullanılan bir diğer yöntem; hastanın parmağını o bölgeye yerleştirmesi ve ağzını yavaşca kapatması şeklindedir ${ }^{10}$. Hastada ortodontik tedavi öncesi alınan radyograflarda yapılan incelemelerde ve detaylı klinik muayenede retromolar bölgede entübasyon tüpü için yeterli boşluğun olduğu tespit edildi.

Duymuş ve ark. ${ }^{12}$ retromolar papille oklüzal düzlem arasındaki mesafeyi ölçtükleri çalışmalarında bu mesafenin erkeklerde 4 mm'nin üzerinde, kadınlarda 4 mm'ye yakın olduğunu tespit etmişlerdir. Truong ve ark. ${ }^{1}$ panaromik radyograflar üzerinde yaptıkları ölçümlerle retromolar bölgenin genişliğini ve yüksekliğini ölçmüşlerdir. Sağ retromolar bölgede ortalama yükseklik ve genişliğin sırasıyla $17.87 \mathrm{~mm}$ ve $17.48 \mathrm{~mm}$; sol retromolar bölgede bu değerlerin $18.07 \mathrm{~mm}$ ve $16.51 \mathrm{~mm}$ olduğunu rapor etmişlerdir. Literatürde belirtilen bu boyutlar yaygın olarak kullanılan entübasyon tüplerinin çapından daha geniştir. Opere edilen hastada $7 \mathrm{~mm}$ çaptaki entübasyon tüpü kullanılmış ve sağ retromolar bölgeden entübasyon rahatlıkla yapılmıştır.

Hava yolu güvenliğini sağlamada sıklıkla kulanılan oral ve nazal entübasyon her zaman uygulanamayabilir. Cerrahlar ve anestezistler alternatif teknikler konusunda hazırlıklı olmalıdır. Tercih edilen entübasyon türü yapılacak operasyon bölgesine ve hastanın hava yolunun anatomisine göre değişiklik gösterebilir. Retromolar bölgede yeterli boşluk varsa retromolar entübasyon tekniği ortognatik cerrahi ameliyatlarında alternatif bir yöntem olarak düşünülebilir. 


\section{KAYNAKLAR}

1. Truong AT, Ahmad B, Cata JP, Martin JW, Truong DT, Rahlfs TF. Measurement of retromolar space dimensions using dental pantomograms for intubation feasibility. Head \& neck 2015.

2. Holzapfel L. Nasal vs oral intubation. Minerva anestesiologica 2003; 69:348-52.

3. Hall CE, Shutt LE. Nasotracheal intubation for head and neck surgery. Anaesthesia 2003, 58:249-256.

4. Arora S, Rattan V, Bhardwaj N. An evaluation of the retromolar space for oral tracheal tube placement for maxillofacial surgery in children. Anesthesia and analgesia 2006; 103:1122-5.

5. Nyarady Z, Sari F, Olasz L, Nyarady J. Submental endotracheal intubation in concurrent orthognathic surgery: a technical note. Journal of craniomaxillo-facial surgery 2006; 34:362-5.

6. Zmyslowski WP, Maloney PL. Nasotracheal intubation in the presence of facial fractures. Jama 1989; 262:1327-8.

7. MacInnis $E$, Baig $M$. A modified submental approach for oral endotracheal intubation. International journal of oral and maxillofacial surgery 1999; 28:344-6.

8. Taglialatela Scafati C, Maio G, Aliberti F, Taglialatela Scafati S, Grimaldi PL. Submentosubmandibular intubation: is the subperiosteal passage essential? Experience in 107 consecutive cases. The British journal of oral \& maxillofacial surgery 2006; 44:12-4.

9. Gibbons AJ, Hope DA, Silvester KC. Oral endotracheal intubation in the management of midfacial fractures. The British journal of oral \& maxillofacial surgery 2003; 41:259-60.

10. Martinez-Lage JL, Eslava JM, Cebrecos AI, Marcos O. Retromolar intubation. Journal of oral and maxillofacial surgery 1998; 56:302-5; discussion 305-6.

11. Dutta A, Kumar V, Saha SS, Sood J, Khazanchi RK. Retromolar tracheal tube positioning for patients undergoing faciomaxillary surgery. Canadian journal of anaesthesia 2005; 52:341.

12. Duymuş ZY, Güldağ Ü, Yanıkoğlu ND. The Relation Of The Occlusal Plane And Retromolar Pad. Atatürk Üniv Diş Hek Fak Derg 2003-2004; 13,14: 23-8.

\author{
Yazışma Adresi \\ Ahmet ALTAN \\ Gaziosmanpaşa Üniversitesi, Diş Hek. Fak. \\ Ali Şevki EREK Yerleşkesi, Tokat/TÜRKİYE \\ Tel: 05057013189 \\ e-mail: dt.ahmetaltan@gmail.com
}

